\title{
REVIEW OF RAILWAY MAINTENANCE METHODS IN GERMANY, ITALY AND INDIA
}

\author{
Naga Sai Dilip Kumar Akula \\ Railway Engineer, \\ IKOS Consulting, Italy
}

\begin{abstract}
Railway maintenance is an important aspect which is not spoken much. This article speaks about the need of it, its importance and its prevalence in three major countries India, Italy and Germany. We start with the fleet size of each countries and methods deployed by each country, and finally concluding the situation in India and how it is being improved.
\end{abstract}

Keywords - Maintenance, Railways, India, Italy, Germany

\section{INTRODUCTION}

Railway management is an essential element which can be seen in the case of public transport systems across the globe. It is essential to infer that railway management systems are required in order to ensure a high rate of effectiveness and efficiency which can be undertaken in the delivery of services to the general population of all countries. In the context of this, technological advancements have saved a pathway for enhanced management and maintenance of railway systems. Maintenance is important to ensure that the infrastructural capacity is maintained and enhanced effectively. Furthermore, it can be analysed that there is a salient requirement of ensuring that the systems are effectively aligned to the prospects which are effectively required. This research will look into the aspect of developing an understanding regarding systems of maintenance in railway management in the countries of India Germany and Italy. The study initially seeks to enumerate the railway systems and further it looks into how technological advances have helped the field of railway maintenance. The study at the end will effectively conclude by identifying why Indian railways has not adopted technological advancements and digital maintenance systems in order to understand the current context of railway management in India,

\section{German, Indian and Italian Railway systems}

The German railway system effectively and efficiently stretches over a distance of 41,315 kilometres and have an electrified track length of 19,857 kilometres as compared to 18,201 kilometres for double tracks (Web.archive.org, 2015).They have a total of 3,188 long-distance vehicles and 17,174 short distance vehicles for passenger transport with an additional 3,134 trains for goods carriage (Web.archive.org,
2015). DB Netz is the largest operator of railways in the case of Germany and further the structure development is also upto them. It can be analysed that the operating income of this company is around 4.797 billion Euros and the net income is 716 million Euros (Cia.gov, 2020). A total revenue of 440.576 billion euros was noted for German railways effectively in the year of 2016 (Cia.gov, 2020). Thus, it can be understood that the German railway system is an extensive and large system which is present.

The Italian railway system in comparison to the German railroad system stretches for a total of 24,227 kilometres and the active lines in these are worth 16,723 kilometres (Ec.europa.eu, 2019). A total ridership of $848,757,000$ was noted in the year of 2017. It has a double rack length of 7,505 kilometres in total and further it has electrified tracks which function on $3 \mathrm{kV}$ DC worth 11,921 kilometres and $25 \mathrm{kV}$ AC worth 1,296 kilometres (Ec.europa.eu, 2019). In the case of the Italian railways it can be understood and ascertained that the overall number of trains are adjoined with the EU and hence proper figures are not decipherable. In contrast to this it can be viewed that the railroad system generates a total revenue of 5.4 billion Euros as discerned in 2018 (Statista.com, 2020). Thus, it can be understood that the Italian Railway system is an effective and efficient system which is conjoined with that of the EU and hence it gains additional efficiency. The total number of employees in Trenitalia of Italy is 27,607 . Thus, it can be ascertained that Trenitalia is much smaller in size than Germany, but it carries much more passengers.

\begin{tabular}{|l|l|l|l|}
\hline Elements & Germany & Italy & India \\
\hline Manpower & 295,653 & 27,607 & 1.23 million \\
\hline Revenue & $\begin{array}{l}€ 40.576 \\
\text { billion }\end{array}$ & $\begin{array}{l}€ \quad 5.4 \\
\text { billion }\end{array}$ & $\$ 28$ billion \\
\hline $\begin{array}{l}\text { Number of } \\
\text { Trains }\end{array}$ & 24,496 & N/A & $\begin{array}{l}2,89,185 \text { freight } \\
\text { wagons, }\end{array}$ \\
\hline
\end{tabular}




\begin{tabular}{|l|l|l|}
\hline & & 74,003 \\
& & passenger \\
& & coaches, \\
& & 12,147 \\
& & locomotives. \\
\hline
\end{tabular}

Table 1: Railway Strength in Three Countries

In the case of Indian Railways, it can be understood that the country has a total track length of 68,155 kilometres and is further expanding. Out of this, 40,576 kilometres worth track is a broad gauge track and these routes are electrified with a $25 \mathrm{kV} 50 \mathrm{HZ}$ AC electric traction (Indianrailways.gov.in, 2019). The Indian railway system annually as of 209 carried a total of " 8.44 billion passengers" in addition to " 1.23 billion tonnes of freight". Indian Railways additionally runs a total of 13,523 passenger trains on a daily basis across a total of 7,321 stations in the subcontinent (Indianrailways.gov.in, 2019). Additionally, a total of 9,146 trains are run daily for freight carriage. In terms of the total manpower of the railway system it can be viewed that it employs 1.23 billion people and additionally it can be understood that the aggregate number of trains in the country is larger than what is run every day (Indianrailways.gov.in, 2019). As of 2019, "Indian Railways" had a "rolling stock of 2,89,185 freight wagons, 74,003 passenger coaches and 12,147 locomotives". The net revenue of Indian Railways from 2018-2019 stood at US \$ 28 billion (Indianrailways.gov.in, 2020). Differences in revenue and the quantity of passengers helps to denote the fact that the operational structure of Indian Railways is much more stable as compared to railway systems in either Italy or Germany. Through constant developments in increasing these aspects even further, Indian Railways can be stated to be the most railway system that is the most prone to achieving even greater efficiency in the future as well.

It can thus be viewed that the size of Indian railways is much superior to that of Trenitalia or even the German railways. It is additionally discerned that Indian railways employ a larger number of individuals and this is more than the combined employment which is created by Germany and Italy effectively. It can be ascertained from the above statistics that the large population of India puts a large emphasis on the maintenance and service delivery of the railways properly. It also is indicative of the fact that the Indian Railways are required to ensure a high rate of efficiency in delivery of product quality as compared to that of Germany and Italy. Further, maintenance requirements are more requirements for Indian railways and it can be viewed that there is an effective need for ensuring new technological developments which can be applied in the context of this country. Comparing the statistics however, it can be analysed that German railways have the highest revenue generation capacity. As compared to this, Indian Railways has a decent amount to buy Italian railways which do not generate as much.

\section{Methods of railway maintenance implemented}

It can be stated that there is an effective need for the maintenance of railway systems effectively and efficiently. Vansteenwegen et al. (2016), indicates that this is indicative of the fact that maintenance is a salient recruitment in the case of railway systems. Maintenance aids in order to ensure a "high rate of efficiency" in the case of railway service delivery and quality control. Additionally, it can be ascertained that there is a definite level of efficacy which is produced through systems which are aimed at delivering proper value to customers. Verbert et al. (2017), indicate that service delivery is important and the requirement of infrastructure development and maintenance also plays a large role in this process. Effectively it can be understood that infrastructure development is essential to ensure that the systems which have been developed are not skewed at any given point of time. It can also be understood from the study of Catelani et al. (2020), that the level of infrastructure development directly puts an impact on the prospect of products and services which are given to customers. In case of railway systems of India, Italy and Germany, it can be ascertained that these three areas have different types of railway systems and these systems require a large amount of maintenance. The interference of technology is extremely important to ensure that costs of maintenance can be effectively lowered and controlled in a proper manner. This helps to provide a low cost quality product and service prospect for customers of a certain economy. It also helps to ensure a higher rate of efficiency and effectiveness which can be gained out of a prospective system which is in place.

In the case of German systems, it can be understood that there is an automated system which is put in place effectively for the purpose of ensuring a higher rate of efficiency. According to Nikitinas and Dailydka (2016), it can be derived that German engineers have additionally defined the system of industry 4.0 which is usable and efficient in the case of locomotive manufacturing. This system focuses on the aspects of total quality management and efficiency improvement for ensuring a proper rate of service delivery. Additionally, it can be assumed that German systems of railway maintenance function on the prospect of integrated automated systems which effectively note and track the condition of existing parts and locomotives and gauge their effectiveness and efficiency. As per the work of Ehrbar, (2016), after this these systems effectively ensure that the maintenance is conducted in accordance with the specific requirements which are noted. It is analysed that this provides a significant amount of efficiency in case of maintenance and effectiveness. It also increases the service delivery potential of German Railway systems as it helps in order to ensure that the technology is updated at all times. This aid in the process of ensuring a higher rate of efficacy and compliance that can be brought around in the aspect of service delivery. This helps in order to ensure that there is an effective and efficient level of 


\section{International Journal of Engineering Applied Sciences and Technology, 2020 \\ Vol. 5, Issue 5, ISSN No. 2455-2143, Pages 235-240 \\ Published Online September 2020 in IJEAST (http://www.ijeast.com)}

compliance which is gained through the overall prospect of the system. Thus, it can be viewed that a proper system of maintenance is essential and it also helps in order for the generation a sound proposition in the case of railways. This increases the cost savings of railways and also enhances the overall prospect of prouctivity which is brought around by a system.

It can be ascertained that the German company DB Netz finalized a deal with HARSCO Rail who provide maintenance and systems for the working of railways efficiently (globalrailwayreview.com, 2019). It can be analysed that HARSCO provides socialization in maintenance systems and areas of multi-function spike pullers, drone anchor squeezers, 3000 utility, speed rail correction systems and the Jupiter II kit and control systems. It integrates data analysis and also provides automated switch inspection and track geometry based vehicle maintenance systems (harscorail.com, 2020). This helps in order to ensure that a comprehensive system is generated for ensuring a high rate of efficiency and effectiveness.

Additionally, it can be analysed that for Trenitalia there are similar systems which are in place. Trenitalia uses the systems of rolling stock management with the help of big data analysis systems which are combined to provide a predictive analysis system which helps in order to ascertain and pre-empt maintenance requirements in the case of a company (globalrailwayreview.com, 2016). This helps in order to generate a certain level of effectiveness and efficiency and it also allows in order to ensure a high rate of effectiveness for the business overall (globalrailwayreview.com, 2016). Ghofrani et al. (2018), indicates that big data analysis helps in order to ensure a high rate of predictability in the timing of maintenance requirements by analysis of trends and patterns of requirements. This helps in order to ensure a high rate of effectiveness.

It is analyzed that the Indian equivalent of the maintenance systems which are used for railway maintenance are that of an automatic railway maintenance system for the management of rolling stock and for the management of effective infrastructure. It can be understood that the Indian Railway system also uses a system of effective and efficient predictive analysis on the basis of time based maintenance requirements which are put into place for the purpose of maintenance and safety of the rolling stock (financialexpress.com 2020), . Additionally, it can be understood that Indian railways have installed an online monitoring of rolling stock (OMRS) system for keeping a track of all the rolling stock and their conditions effectively (financialexpress.com 2020). The entire purpose of the Indian system is to detect effective rates of defects in the rolling stocks before any risk arises out of the same (financialexpress.com 2020). This helps in order to increase the efficiency of the large railway system which is present in the case of India.

\section{Technological advances in field of railway maintenance}

In the field of railway maintenance systems it can be understood that there is an effective rate of efficiency which is to be undertaken in the case of essential maintenance and their activities. Furthermore, it can be analysed that there is an explicit need for advancement in technological fonts due to the changing nature of the customer demographic and modern market needs. These are effective and efficiently required for ensuring that overall the safety and security of tech storms in the case of the railway systems all across the world are maintained and ensured. This also helps in order to generate a greater rate of efficiency.

The first system which is important to be looked into is the system of rolling stock management by the use of big data analysis. It can be effectively determined that the use of big data analysis has helped in order to generate a significant amount of understanding regarding the specific requirements which represent in the case of a business. Thaduri et al. (2015), states that big data analytics provide an overview of the systems which are used effectively in the case of the markets. It can be analysed that big data analytics collects all the important data which is effectively required and it enhances the prospect of understanding the salient requirements which are used effectively. Furthermore, it can be understood that the system of big data analytics helps in order to ensure A higher rate of efficiency in the overall prospect of maintenance. This happens as it allows for discerning and investigating the different requirements which are present on the basis of data trends which have been collected and observed. This helps in analysing the component and small risks which build up and thus regular maintenance systems can be aligned to this system to ensure a high rate of efficiency to the rolling stock.

Another effective system which can be used is the system of effective predictive analysis which is again supported by the system of big data analytics. In case of the predictive analysis system it can be analysed that there is an important need for ensuring a high rate of effectiveness and it detects and predicts the risks which may effectively occur in a certain system. Ghofrani et al. (2018), indicates that the predictive analysis system helps in order to ensure and effective generate a high rate of effectiveness and efficiency in terms of the overall rail management system. It helps to gauge the requirements of the rolling stocks which are present in the case of railway systems. It can be understood that the predictive railway systems help in order to outline the effective need for maintenance which is undertaken. This helps in order to provide and draw data from the big data analytical systems and effectively apply it to the case of the companies. It also helps in order to ensure a high rate of effectiveness and efficiency.

Thus it can be analysed that a combination of these systems helps in order to generate a high and effective rate of efficiency in railway management. It also helps in order to ensure a high level of efficiency in management of the railway 


\section{International Journal of Engineering Applied Sciences and Technology, 2020 \\ Vol. 5, Issue 5, ISSN No. 2455-2143, Pages 235-240 \\ Published Online September 2020 in IJEAST (http://www.ijeast.com)}

infrastructure. Additionally, these systems not only increase passenger safety and security but also reduce costs. This helps in ensuring that lower arte of damages occur and the damages do not multiply to create large risks. It also ensures effective rates of quality which can be maintained through the scope of these systems effectively. This also helps in order to ensure a higher rate of compliance and effectiveness.

\section{Indian railways and the reasons for not adopting new methods of maintenance}

Discerning from the information which has been gathered it can be understood that in comparison to the German infrastructure and Italian infrastructure of railway systems the Indian railway systems effectively have a high rate of competitiveness. It can be analysed that Indian tracks have a large number of electrically functioning tracks alongside the prospect of a higher rate of infrastructure than that of its Italian contemporary. The German systems are greater in their efficiency and have almost similar infrastructure to that of Indian railway system. However, in terms of revenue generation it is inferred that the German railways perform much better. However, it is analysed that the Indian railways have placed systems into the maintenance and performance processes which help in order to generate a large level of effectiveness and efficiency for the same. This helps in order to ensure a high level of efficiency which can be undertaken.

In the case of the country of India it can be inferred that the overall population of the country is very large. Böckin et al. (2020), indicates that greater use of a resource is the perspective of wearing the resource down more easily. Thus, in the context of India it can be viewed that the railways are cheap and a common form of transport for a high number of passengers. This leads to a lot of wear and tear of the infrastructure which has already been put in place. Additionally, it can be understood that there is a high requirement of efficiency in these systems as the trains in India carry a large amount of passengers every day. Normal reliability of travelling depends on this asset and it also is a key performance factor which helps in order to generate a high rate of effectiveness in the economy. Thus, it is imperative that the Indian railway systems need to be equipped with the best possible technology in order to generate a high rate of efficiency. This also helps in order to ensure that the infrastructural damage can be mitigated so as to reduce overall spending in an effort to cut costs for this public resource.

\{ in addition to the prospect of population another key factor which needs to be understood is that of passenger safety. Arslan and Teriyaki (2020), indicates that passenger safety in railways is important as it helps in ensuring reliability. The Indian system of railways has a lot of people dependent on the same and it is imperative that safety and security is maintained efficiently to ensure a high level of reliance on the same. Thus, it can be viewed that the use of big data analytics for predictive model generation in case of operational efficiency creation is important. Furthermore, Murugan (2020), indicates that overall safety is essential and it also helps in order to generate a large rate of effectiveness and efficiency which is required to ensure a high rate of security as well. Predictive analysis systems which are incorporated in the Indian contexts help in order to generate a large level of understanding of the requirements of maintenance and these help in order to ensure that the risks are mitigated by repairs and maintenance of the products through which services are delivered. This helps in order to ensure a high rate of effectiveness and efficiency in the overall systems which re incorporated in the case of the country

In case of the Indian systems it can also be analysed that the implementation of the OMRS system is required as there is a large rolling stock which goes out every-day for the entire country. This is essential as it helps in order to generate a proper evaluation and monitoring system which is to be put in place in the text of the railway system. This monitoring and evaluation system is informative of risks and problems which may occur. Wang et al. (2020), indicate that OMRS systems help in order to generate a good level of strategic compliance in service delivery. The implementation of these helps the Indian Railway system to generate a high rate of service delivery and good level of quality aligned with safety and security for the passengers of the same.

One of the army requirements of the Indian systems in the terms of railways are however, the systems of Industry 4.0. This is required for ensuring that the maintenance and safety is not only a control measure. Sahal et al. (2020), indicates that industry 4.0 seeks to deliver appropriate manufacturing and service delivery quality management through the start and end of a certain manufacturing process. Thus, industry 4.0 is essential for a country like India where the rate of depreciation and damage of infrastructure is high. Industry 4.0 is a key system which can be input into the case of the Indian railway system which would overall impact the prospect of maintenance through the means of quality management in manufacturing processes of infrastructure. This would not only cut costs for the railway system in the long-run but it would also generate a high level of effectiveness overall and this would help to ensure a high rate of compliance to safety and security protocols as well.

It can be understood that most of the systems in case of Indian railways are updated, however, there is still requirement and scope for further addition to ensure that the systems can be effective and efficient overall.

\section{CONCLUSION}

Summarising the findings of this study it can be inferred that there is an effective rate of conclusively that can be drawn out in terms of the overall systems in the three railways. It can be analysed that the Indian railway system is not below par and it is heavily suited to take the laid which has been described. 


\section{International Journal of Engineering Applied Sciences and Technology, 2020 \\ Vol. 5, Issue 5, ISSN No. 2455-2143, Pages 235-240 \\ Published Online September 2020 in IJEAST (http://www.ijeast.com)}

However, it can also be inferred that the Indian railway system essentially is functioning at a breakeven and has not been able to achieve its full efficiency. This indicates as to why the level of effective quality is lower and the revenue generated is also lower.

It can be viewed that there is a need for implementing the Industry 4.0 system in addition to big data analytics procedures and predictive analysis systems. The existing predictive analysis system is a huge efficiency area for the Indian railways and it also provides a sound amount of effectiveness in terms of efficiency. Additionally, it can be analysed that the systems of online monitoring of railway systems helps in order to effectively improve the safety quotient of Indian Railways. Additionally, it can also be inferred that a combination of these aspects makes it very advantageous and safe.

However, owing to the great population size the pressure on these systems is greater and thus, it can be inferred that Industry 4.0 will be advantageous for the Indian railway maintenance and service delivery prospects. This is because the process of industry 4.0 falls in line with TQM requirements and seeks to provide high quality delivery. This will allow for Indian Railways to generate an extended scope of their operations and also ensure that safety and security for passengers are maintained in the overall process. It will also add to the existing big data analytical and predictive risk measurement systems and provide greater efficiency to the overall system of OMRS as well. Thus, it can be understood that a higher level of effectiveness can be instilled into the Indian railway management and maintenance systems and this would also allow in reduction of risks. It conversely would allow the generation of economies of scale for larger scales of revenue generation even after cost cutting. This provides a double benefit for the passengers and the railways.

\section{Acknowledgements}

I would like to thank all those people who have helped me in order to complete this project. Primarily, I would like to thank my professor who has helped me for review

Further, I would like to thank my family and all of my friends who have been understanding through the overall course of the research and have supported me unwaveringly. I would not have been successful without them.

\section{REFERENCE}

1 Arslan, B. and Tiryaki, H., (2020). Prediction of railway switch point failures by artificial intelligence methods. Turkish Journal of Electrical Engineering \& Computer Sciences, 28(2), (Pg.1044-1058).

2 Böckin, D., Willskytt, S., André, H., Tillman, A.M. and Söderman, M.L., (2020). How product characteristics can guide measures for resource efficiency-A synthesis of assessment studies. Resources, Conservation and Recycling, 154(6), (Pg.104582-104673).
3 Catelani, M., Ciani, L., Guidi, G. and Patrizi, G. (2020). Maintainability improvement using allocation methods for railway system. ACTA IMEKO, 9(1), (Pg.10-17).

4 Cia.gov, (2020). World Factbook. Available at: https://www.cia.gov/library/publications/the-world-

factbook/rankorder/2121rank.html [Accessed on: 2 September, 2020]

5 Ec.europa.eu, (2019). Railway passenger and transport statistics - quarterly and annual data. Available at: https://ec.europa.eu/eurostat/statistics-

explained/pdfscache/7066.pdf [Accessed on: 2 September, 2020]

6 Ehrbar, H. (2016). Building Information Modelling-A new tool for the successful implementation of major projects of German railways/Building Information Modelling-Ein neues Werkzeug zur erfolgreichen Realisierung von Großprojekten der Deutschen Bahn. Geomechanics and Tunnelling, 9(6), (Pg.659-673).

7 financialexpress.com, (2020). Indian Railways installs unique system for a automatic system of wheels; big step towards passenger safety. Available at: https://www.financialexpress.com/infrastructure/railways/i ndian-railways-installs-unique-system-for-automaticinspection-of-wheels-big-step-towards-passengersafety/1832718/ [Accessed on: 6 September, 2020]

8 Ghofrani, F., He, Q., Goverde, R.M. and Liu, X., (2018). Recent applications of big data analytics in railway transportation systems: A survey. Transportation Research Part C: Emerging Technologies, 90(2), (Pg.226-246).

9 globalrailwayreview.com, (2016). Trenitalia improves rolling stock maintenance using big data. Available at: https:/www.globalrailwayreview.com/article/28433/bigdata-trenitalia-rolling-stock-

maintenance/\#: :text=Trenitalia\%20improves\%20rolling\% 20stock\%20maintenance $\% 20$ using\%20big\%20data\&text $=$ Rolling\%20stock\%20maintenance $\% 20$ is\%20an,analytics \% 20and\%20in\%2Dmemory\%20computing. [Accessed on: 4 September, 2020]

10 globalrailwayreview.com, (2019). DB etz awards major rail maintenance equipment order to Harsco Rail. Available at: https://www.globalrailwayreview.com/news/88611/dbnetz-harsco-rail-maintenancemachinery/\#: :text=DB\%20Netz\%20awards\%20major\%2 0rail $\% 20$ maintenance $\% 20$ equipment $\% 20$ order $\% 20$ to $\% 20$ Harsco\%20Rail,-

183\&text=The $\% 20$ agreement $\% 20$ is $\% 20$ the $\% 20$ first,total $\%$ 20value $\% 20$ of $\% 20 \% 24290 \% 20$ million. [Accessed on: 6 September, 2020]

11 harscorail.com, (2020). Maintenance Systems. Available at:

https://www.harscorail.com/?searchword=maintenance\&se archphrase $=$ any \&limit $=20 \&$ ordering $=$ newest $\&$ view $=$ searc h\&option=com_search [Accessed on: 6 September, 2020] 


\section{International Journal of Engineering Applied Sciences and Technology, 2020 \\ Vol. 5, Issue 5, ISSN No. 2455-2143, Pages 235-240 \\ Published Online September 2020 in IJEAST (http://www.ijeast.com)}

12 Indianrailways.gov.in (2019). Indian Railways Yearbook 2018-2019. Available

at: https://www.indianrailways.gov.in/railwayboard/uploads/d irectorate/stat_econ/Year_Book/Year\%20Book\%20201819-English.pdf [Accessed on: 4 September, 2020]

13 Indianrailways.gov.in (2020). Budget at a glance. Available at: http://indianrailways.gov.in/railwayboard/uploads/director ate/finance_budget/Budget_2019-

20_Final/Statement $\% 20$ of\%20Railway\%20Receipts\%20an d\%20Expenditure_Regular\%20Budget\%202019-20.pdf

[Accessed on: 4 September, 2020]

14 Murugan, B.M., (2020). A Study on Passenger Satisfaction Towards Rail Service in Indian Railways. Studies in Indian Place Names, 40(50), (Pg.4282-4287).

15 Nikitinas, V. and Dailydka, S. (2016). The models of management of railway companies in the European Union: Holding, the German Experience. Procedia engineering, 134(21), (Pg.80-88).

16 Sahal, R., Breslin, J.G. and Ali, M.I., (2020). Big data and stream processing platforms for Industry 4.0 requirements mapping for a predictive maintenance use case. Journal of Manufacturing Systems, 54(2), (Pg.138-151).

17 Statista.com (2019). Revenue of Trenitalia in Italy, 20162018. Available at: https://www.statista.com/statistics/683045/operatingincome-of-the-italian-railway-companytrenitalia/\#: :text=Revenue\%20of\%20Trenitalia\%20in\%2 OItaly\%202016\%2D2018\&text=From $\% 202016 \% 20$ to $\% 20$ $2018 \% 2 \mathrm{C} \% 20$ Italian,over\%20the $\% 20$ period $\% 20$ of $\% 20$ co nsideration. [Accessed on: 3 September, 2020]

18 Thaduri, A., Galar, D. and Kumar, U., (2015). Railway assets: A potential domain for big data analytics. Procedia Computer Science, 53(5), (Pg.457-467).

19 Vansteenwegen, P., Dewilde, T., Burggraeve, S. and Cattrysse, D., (2016). An iterative approach for reducing the impact of infrastructure maintenance on the performance of railway systems. European Journal of Operational Research, 252(1), (Pg.39-53).

20 Verbert, K., De Schutter, B. and Babuška, R., (2017). Timely condition-based maintenance planning for multicomponent systems. Reliability Engineering \& System Safety, 159(8), (Pg.310-321).

21 Wang, K., Cao, W., Xu, L., Yang, X., Su, Z., Zhang, X. and Chen, L., (2020). Diffuse ultrasonic wave-based structural health monitoring for railway turnouts. Ultrasonics, 101(9), (Pg.106031-106077).

22 Web.archive.org (2015). Interactive key figure components. Available at: https://web.archive.org/web/20171227235427/http://ib.deu tschebahn.com/2016/en/interactive-key-figurescomparison/at-a-glance/ [Accessed on: 2 September, 2020] 